International Journal of Heat and Mass Transfer DRAFT

\title{
Conjugate Heat Transfer Analysis of the Effects of Impingement Channel Height for a Turbine Blade Endwall
}

\author{
Amy Mensch and Karen A. Thole \\ Department of Mechanical and Nuclear Engineering \\ The Pennsylvania State University \\ University Park, PA, USA
}


International Journal of Heat and Mass Transfer DRAFT

\title{
Conjugate Heat Transfer Analysis of the Effects of Impingement Channel Height for a Turbine Blade Endwall
}

\author{
Amy Mensch and Karen A. Thole \\ Department of Mechanical and Nuclear Engineering \\ The Pennsylvania State University \\ University Park, PA, USA
}

\begin{abstract}
Advancements in cooling for applications such as gas turbines components require improved understanding of the complex heat transfer mechanisms and the interactions between those mechanisms. Critical cooling applications often rely on multiple thermal protection techniques, including internal cooling and external film cooling in gas turbine airfoils, to efficiently cool components and limit the use of coolant. Most research to quantify the effectiveness of such cooling technologies for gas turbine applications has isolated internal and external cooling in separate experiments. The research presented in this paper uses a conjugate heat transfer approach to account for the combined effects of both internal and external cooling. The geometry used for this study is a turbine blade endwall that includes impingement and film cooling as well as the relevant conduction through the endwall. Appropriate geometric and flow parameters were scaled to ensure engine relevant dimensionless temperatures were obtained. Using the conjugate heat transfer approach, the effect of varying the height of the impingement channel was examined using spatially resolved external wall temperatures obtained from both experiments and simulations. A one-dimensional heat transfer analysis was used to derive the average internal heat transfer coefficients from the experimental results. Both experiments and simulations showed good agreement between area averaged cooling effectiveness and impingement heat transfer coefficients. The cooling effectiveness and heat transfer coefficients peaked for an impingement channel height of around three impingement hole diameters. However, the heat transfer coefficients were more sensitive than the overall effectiveness to the changes in height of the impingement channel.
\end{abstract}

\section{KEYWORDS}

Conjugate heat transfer $\quad$ Film cooling

Gas turbine endwall

Impingement

\section{INTRODUCTION}

A continuing challenge in advanced cooling applications is understanding the interaction between multiple heat transfer mechanisms, which is referred to as conjugate heat transfer. Conjugate heat transfer is the combined result from convective heating and cooling, conduction within the walls, and radiation heat transfer. In many applications such as along gas turbine components, the most effective cooling configurations are often three-dimensional and are surrounded by complicated flow fields and thermal fields. In a gas turbine engine, the airfoil and endwall surfaces simultaneously experience convective heating from the hot combustion gases and convective cooling from air supplied by the compressor that has bypassed the combustor. The convective cooling occurs both internal to the airfoil, such as through jet impingement, and external to the airfoil, such as through small angled holes in the airfoil walls providing what is known as film cooling. In combined impingement and film cooling, the cooling air impinges on the internal walls, and then passes through the film cooling holes to generate a protective film of coolant on the outer wall. The combination of the convective and conductive heat transfer processes determines the resulting wall temperature, which governs the service life of the turbine components. Therefore, accurate predictions of component temperature are critical to evaluate cooling technologies.

Current practices to predict turbine component temperatures involve calculating the solid conduction using analytical or numerical tools while applying convective boundary conditions based on separate internal and external experiments or analyses. Most literature in gas turbine heat transfer reports either heat transfer coefficients measured with a constant heat flux boundary condition or adiabatic film cooling effectiveness measured with an adiabatic boundary condition. The latter is applied in analytical or numerical tools to represent the reference temperature for external convection in the presence of film cooling. An alternative to this isolated heat transfer analysis is direct determination of the non-dimensional wall temperature, referred to as the overall effectiveness $(\phi)$, since that is the value of most interest to turbine designers. To determine the non-dimensional temperature, a conjugate experiment or simulation must use a properly scaled conjugate model that couples the convective heat and cooling and solid conduction.

As will be discussed in the following sections, recent experiments and simulations have begun to investigate conjugate heat transfer effects to provide scaled metal temperatures. This study focus on the conjugate heat transfer results due to variations in the 
internal impingement cooling geometry, building upon the results for a blade endwall with impingement and film cooling by Mensch et al. [1,2]. Conjugate experiments and computational simulations are used to examine the influence of internal impingement cooling geometry on wall temperatures and internal heat transfer coefficients. The convective cooling under the endwall of a turbine airfoil is of interest in this study, specifically the effects of the distance between the impingement plate and the endwall target.

\section{NOMENCLATURE}

A Area

Bi Biot number $\left(h_{\infty} t / k_{w}\right)$

$C_{a x} \quad$ Axial chord length

$C_{d} \quad$ Discharge coefficient

$c_{p} \quad$ Specific heat

$D \quad$ Hole diameter

$D R \quad$ Density ratio $\left(\rho_{c} / \rho_{\infty}\right)$

$H \quad$ Impingement gap height

$h \quad$ Convective heat transfer coefficient

$k \quad$ Thermal conductivity

$L \quad$ Length

$M \quad$ Blowing ratio $\left(\rho_{c} U_{c} / \rho_{\infty} U_{\infty}\right)$

Ma Mach number

$\dot{m} \quad$ Mass flow rate

$N u_{D, i} \quad$ Internal Nusselt number $\left(h_{i} D / k_{c, i n}\right)$

$P \quad$ Pressure

$p \quad$ Pitch length

$q \quad$ Heat flux

Re Mainstream Reynolds number $\left(\rho_{\infty} U_{\infty} C_{a x} / \mu_{\infty}\right)$

$\operatorname{Re}_{D} \quad$ Impingement Reynolds number $\left(\rho_{c, i n} U_{c} D / \mu_{c, i n}\right)$

$S \quad$ Blade span

$T \quad$ Temperature

$t \quad$ Thickness

$U \quad$ Streamwise velocity

$u^{\prime} \quad$ Fluctuating velocity

$x, y, z \quad$ Global coordinates, where $\mathrm{x}$ is blade axial

direction

\section{$\underline{\text { Greek }}$}

$\delta$

Boundary layer thickness

$\mu \quad$ Dynamic viscosity

$\rho \quad$ Density

$\phi \quad$ Overall effectiveness $\left(T_{\infty}-T_{w}\right) /\left(T_{\infty}-T_{c, \text { internal }}\right)$

\section{Subscripts, Accents}

$\begin{array}{ll}\overline{(\bar{C})} & \text { Laterally averaged } \\ \text { avg } & \text { Area averaged } \\ c, \text { inlet } & \text { Average } \\ c, \text { Coolant at film cooling hole inlet } \\ i & \text { Coolant upstream of impingement plate } \\ \infty & \text { Internal } \\ \text { film } & \text { Mainstream or external } \\ l o c & \text { External driving temperature location } \\ o & \text { Local } \\ s & \text { Impingement cooling only } \\ \text { tot } & \text { Static } \\ w & \text { Total } \\ & \text { Wall }\end{array}$




\section{RELEVANT LITERATURE}

Numerous experiments with constant temperature and constant heat flux boundary conditions are found in the literature for turbine airfoils, but these studies provide only a portion of the required boundary condition information to predict the actual endwall temperature. Internal heat transfer coefficients for engine relevant geometries of internal impingement cooling can be found in the papers by Florschuetz et al. [3] and Hollworth and Dagan [4]. These two studies provide correlations for the $N u$ as functions of jet Re and geometric parameters with a constant temperature boundary condition. Florschuetz et al. [3] considered staggered impingement jet geometries where the coolant was extracted laterally from one side. The authors found that the crossflow that developed in the channel generally degraded the heat transfer coefficient from the first row of jets to the exit row. Hollworth and Dagan $[4,5]$ measured the $\mathrm{Nu}$ for staggered impingement geometries where the coolant is extracted through angled holes in the target plate, which simulates a configuration with combined impingement and film cooling. Hollworth and Dagan [4] provided a correlation for the area-averaged $\mathrm{Nu}$ for configurations with impingement and film cooling extraction. Although some geometric parameters are included in the impingement correlations, the ratio of impingement holes to extraction holes is not included, and this ratio may differ for realistic endwall geometries such as the one presented in our study. The impingement heat transfer effects of certain parameters, such as the distance between the impingement plate and the target, $H$, were reviewed by Viskanta [6]. The $N u$ for the impingement jets usually varied with the impingement channel height to hole diameter ratio, $H / D$, with a maximum occurring between $H / D$ of $1.5-4$ depending on the specific jet arrangement and method of $N u$ measurement $[3,4,6]$. For impingement with film cooling extraction, Hollworth and Dagan [4] found that for the smallest spacing between impingement jets, $5 D$, there was not much change in $N u$ for a wide range of $H / D=0.5-6.0$.

Conjugate heat transfer models to determine the overall effectiveness, $\phi$, or non-dimensional wall temperature, have been applied to various geometries including flat plates, leading edge models, and full turbine airfoil models. The conjugate effects of conduction and film cooling for a flat plate were examined by Wang and Zhao [7] with a two-dimensional slot geometry. They compared the results obtained for different wall boundary conditions including adiabatic and conjugate walls. While the adiabatic wall temperatures varied across the surfaces, the scaled conducting wall temperature, $\phi$, was relatively uniform. In the gas turbine industry, the conduction in the metal components is often assumed to dominate the heat transfer, smear temperature gradients, and produce nearly constant $\phi$. However, even for the case of a very low Biot number, $B i \sim 0.03$, Wang and Zhao [7] showed that $\phi$ varied locally and was not uniform across the surface. Conjugate heat transfer experiments for turbine applications were pioneered by Hylton et al. [8,9] and Turner et al. [10]. Although the $B i$ was not identified, these studies improved the understanding of the thermal fields of a conducting vane, and provided experimental data for benchmarking computational work.

Studies including both experimental and computational conjugate heat transfer results provide important comparisons for validation of computational design tools. Papanicolaou et al. [11] compared computational simulations of conjugate heat transfer to experimental measurements made on a flat plate with film cooling for a $B i \sim 3$ and a $B i \sim 0.08$. Their effectiveness results highlighted the large differences in temperature distribution that are observed for experiments with different $B i$. Panda and Prasad [12] also compared experimental and computational results for a flat plate with film cooling with and without additional cooling by internal impingement jets. The authors considered conduction through the wall, but did not report the $B i$ of their model. The simulations showed good agreement with the experimental results along the plate centerline.

Albert et al. [13] developed a one-dimensional heat transfer equation, which demonstrated that it is essential to match $B i$ as well as the ratio of external-to-internal heat transfer coefficients, $h_{\circ} / h_{i}$, in order to acquire relevant temperature data in a conjugate experiment. The first experiments to use an engine matched $B i$ experimental model were completed by Sweeney and Rhodes [14] for a three-dimensional flat plate with internal impingement and film cooling. Between the impingement plate and the wall were heat transfer enhancement features in a Lamilloy ${ }^{\circledR}$ snowflake design. Their results showed that impingement cooling dominated over film cooling in the distribution of external wall temperatures. The temperature distribution varied with different arrangements of impingement jets. When the jets were tightly spaced, the temperature distribution was quite uniform. When the jet spacing increased, non-uniformities were observed the external wall temperature.

Additional matched $B i$ experiments and simulations were performed by Maikell et al. [15] and Dobrowolski et al. [16] on a leading edge model with internal jet impingement and external film cooling. The effects of jet impingement were applied to the simulations by setting the internal wall temperature distribution equal to the measured temperature distribution from the experiments. The simulated heat flux results were compared to the predicted heat flux, calculated using the adiabatic wall temperature and the $h_{\infty}$ obtained from a constant wall heat flux simulation. Mouzon et al. [17] and Ravelli et al. [18] tested the same leading edge model but with shaped film cooling holes with and without impingement cooling, and found there was little difference when impingement was added due to the high effectiveness of the film cooling used. Ravelli et al. [18] varied the size and location of the impingement holes relative to the film cooling holes in the numerical portion of the study, but the overall effectiveness was not significantly changed. However, the arrangement of holes affected the internal flow recirculation and distribution of coolant between the film cooling holes. Williams et al. [19] and Dyson et al. [20] performed experiments and computations, respectively for the suction side of a vane model having an engine matched $B i$ of 0.4-1.6 with film cooling and impingement. Williams et al. [19] also measured the overall effectiveness with impingement cooling only by blocking some film cooling holes in the suction side row. The un-blocked film 
cooling holes provided a path for the impingement jets to exhaust, which minimized the alteration of the impingement flow path and isolated the film cooling external effects from the film cooling effects on the impingement flow.

The overall thermal performance of a turbine endwall geometry with impingement and film cooling was investigated by Mensch et al. [1,2] with matched $B i$ experiments and simulations. The external heat transfer for an endwall differs from that of a flat plate, leading edge or airfoil surface, due to the influence of passage secondary flows including the horseshoe and passage vortices. The passage vortices that develop along the endwall skew the direction of endwall flow and locally increase the external heat transfer coefficient, as measured by Kang and Thole [21]. The distribution of the external endwall heat transfer coefficients for the airfoil geometry in this study was investigated by Lynch et al. [22] through both experiments and computational predictions with a constant wall heat flux boundary condition. For the conjugate endwall studies [1,2], the endwall was cooled with the same cooling features as the current study. Results indicated that the internal impingement cooling had a greater influence than film cooling on the scaled endwall temperatures.

Since internal impingement cooling is important in turbine endwall heat transfer, the current study seeks to examine the impact on overall effectiveness of varying geometric parameters relative to impingement cooling. Although data are available for the dependence on geometric parameters of heat transfer coefficient, previously available experimental databases do not include data derived from conjugate experiments. For a conducting leading edge, Ravelli et al [18] found that the overall effectiveness was not greatly affected by a limited changed in impingement parameters. The current study investigates the effects on the performance of a conducting endwall, for a wide range of impingement channel heights.

\section{SIMULATION METHODS}

\subsection{CONJUGATE METHODOLOGY}

To achieve relevant, scaled wall temperature data, a conducting surface with appropriate non-dimensionless parameters must be matched between the experimental model and the actual turbine airfoil being simulated. This matching ensures that the scaled results best represent the behavior of the turbine surface, considering all of the heat transfer and cooling relevant to the wall. The experimental model in this study incorporates external film cooling, wall conduction, and internal impingement jet cooling, thereby including the conjugate effects. Note that for most turbine blade applications, radiation is not included since the blades do not see the combustor and nearly all the surfaces seen by a blade are at similarly high temperatures.

A simple schematic of the heat transfer model showing the pertinent temperatures and properties is shown in Fig. 1a for a configuration with impingement and film cooling and Fig. 1b for impingement cooling only. All non-dimensional temperatures are scaled by the overall temperature difference between the hot mainstream temperature, $T_{\infty}$, and the internal coolant temperature at the plenum supplying the coolant, $T_{c, i n}$. The reference temperature for the external convection coefficient with film cooling is assumed to be a temperature representing the overall film temperature, $T_{\text {film }}$, (typically the adiabatic wall temperature) which accounts for the mixing of the coolant with the mainstream [23]. The non-dimensional film temperature is assumed to be independent of the boundary condition at the wall, and only a function of geometry and the coolant and mainstream Reynolds numbers. The temperature of the coolant after impingement, called $T_{c, \text { inlet }}$, is approximately the same in both cases, as verified by thermocouple measurements. The equivalence of these temperatures indicates that the total heat transferred from the internal endwall surface to the coolant is the same regardless of how the coolant exits the channel.

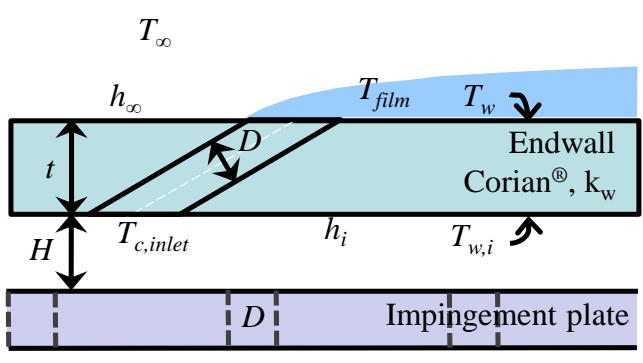

$T_{c, \text { in }}$

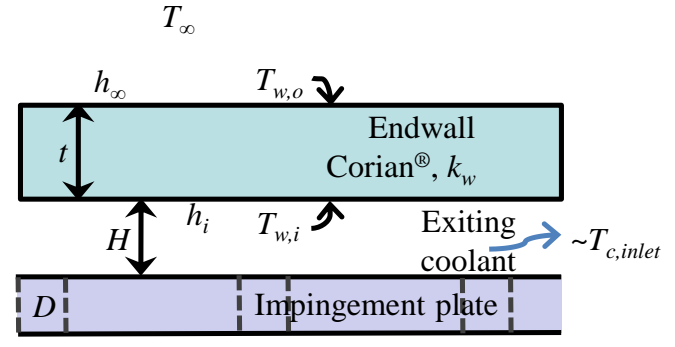

$T_{c, i n}$

(a)

(b)

Fig. 1. Important parameters and temperatures of the conjugate wall with (a) film and impingement cooling and (b) impingement cooling only.

To illustrate the non-dimensional parameters influencing the heat transfer, equation (1) is presented for the overall effectiveness, $\phi$. Equation (1) is derived by equating the external convection heat flux to the overall one-dimensional heat transfer from $T_{f i l m}$ to $T_{c, \text { in }}$ 
for the general case of impingement and film cooling shown in Fig. 1a. When there is no film cooling, such as in Fig. $1 \mathrm{~b}, T_{\text {film }}$ is equal to $T_{\infty}$, and the non-dimensional temperature in equation (1) becomes zero. Equation (1) is similar to the one presented recently for studies with internal and external cooling, such as Williams et al. [19], except for the use of $T_{\text {film }}$ as the driving temperature, rather than the adiabatic wall temperature.

$$
\phi=\frac{T_{\infty}-T_{w}}{T_{\infty}-T_{c, i n}}=\frac{1-\left(\frac{T_{\infty}-T_{\text {film }}}{T_{\infty}-T_{c, i n}}\right)}{1+B i+h_{\infty} / h_{i}}+\left(\frac{T_{\infty}-T_{f i l m}}{T_{\infty}-T_{c, i n}}\right)
$$

Equation (1) demonstrates the importance of matching the geometry and the non-dimensional parameters of $B i$, and $h_{\infty} / h_{i}$ for conjugate studies to be relevant to actual conditions. The ranges of the non-dimensional parameters matched to that of a gas turbine are given in Table 1 showing that the model meets the criteria of matching the $B i$ and $h_{\infty} / h_{i}$. The external heat transfer coefficient, $h_{\infty}$, is enhanced from that of a flat plate due to passage secondary flows [24]. Although the $h_{\infty}$ measured does not account for film cooling, film cooling augmentation on the endwall is assumed to be minor $[25,26]$. The internal heat transfer coefficient, $h_{i}$, is enhanced with impingement jet cooling. To estimate the average $h_{i}$ in the design of the experiment, Nusselt number, $N u$, correlations in the literature for impingement cooling with and without crossflow $[3,4]$ are applied. The range of $h_{\circ} / h_{i}$ values has some variation with blowing ratio, but stays reasonably close to 1 . A reasonable $B i$ range is achieved by scaling the endwall thickness and thermal conductivity through the use of Corian ${ }^{\circledR}$, a thermally conductive material, to manufacture the endwall. Flow conditions and geometric scaling of the model were designed to match the non-dimensional film temperature.

Table 1. Conjugate Endwall Parameters

\begin{tabular}{lcc}
\hline & Model Design & Typical Endwall \\
\hline$M_{\text {avg }}$ & $1.0,2.0$ & $1.0-2.0$ \\
$k_{w}, \mathrm{~W} / \mathrm{m}-\mathrm{K}$ & $0.99-1.06$ & 22 \\
$t, \mathrm{~cm}$ & 1.27 & 0.20 \\
$h_{\infty} h_{i}[3,4,24]$ & $0.4-2.5$ & 1 \\
$B i=h_{\infty} t / k$ & $0.3-0.7$ & 0.27 \\
\hline
\end{tabular}

As a check, the internal heat transfer coefficient can be calculated using measured temperatures from a simple one-dimensional analysis with knowledge of three temperatures. Considering the general case shown in Fig. 1(a), the relevant temperatures are $T_{\text {film }}$, $T_{w}, T_{w, i}$, and $T_{c, i n}$. The mainstream temperature, $T_{\infty}$, cannot be used directly since it is not the external driving temperature with film cooling as previously described. Since $T_{\text {film }}$ is difficult to quantify, the latter three temperatures are used to determine $h_{i}$. Just as the external wall temperature, $T_{w}$, is non-dimensionalized as $\phi$, the data for $T_{w, i}$ can be non-dimensionalized by the mainstream and coolant temperatures to define an internal overall effectiveness, as shown in Eq. (2).

$$
\phi_{i}=\frac{T_{\infty}-T_{w, i}}{T_{\infty}-T_{c, i n}}
$$

To derive an equation for $h_{i}$ using the coolant and wall temperatures, the internal convection heat flux is set equal to the onedimensional conduction heat flux through the wall. Equating two adjacent modes of heat transfer limits the impact of threedimensional effects. This approach generates the following Eq. (3) for $h_{i}$ obtained from the experiments. The $h_{i}$ obtained from the computational results is directly calculated from the local heat flux and temperatures, shown in equation (4).

$$
\begin{gathered}
h_{i, \text { meas }}=\frac{k_{w}}{t} \frac{\left(\phi_{i}-\phi\right)}{\left(1-\phi_{i}\right)} \\
h_{i, \text { pred }}=\frac{q_{w, i}}{\left(T_{w, i}-T_{c, \text { in }}\right)}=\frac{q_{w, i}}{\left(T_{\infty}-T_{c, i n}\right)\left(1-\phi_{i}\right)}
\end{gathered}
$$

\subsection{EXPERIMENTAL METHODS AND UNCERTAINTY}

Steady state experiments were performed for the endwall of a linear blade cascade inserted into a large scale, low speed, closed loop wind tunnel depicted in Figs. $2 \mathrm{a}$ and $2 \mathrm{~b}$. The wind tunnel split into mainstream and coolant flow paths upstream of the test section, as shown in Fig. 2a where the tunnel widens. The coolant flow was diverted into the top blue section. The mainstream flow continued through the center portion of the wind tunnel, which contained a heater bank, turbulence grid, and other flow conditioning elements. More details regarding the wind tunnel can be found in [24]. Mainstream temperatures were measured by five thermocouples on a rake inserted 0.5 blade axial chords upstream of the blade leading edge at multiple locations across the cascade. The measured mainstream temperatures were averaged to determine $T_{\infty}$. The maximum variation from the average $T_{\infty}$ for any location 
was $\pm 0.6^{\circ} \mathrm{C}$. A Pitot probe, also inserted $0.5 \mathrm{C}_{\mathrm{ax}}$ upstream, was used to measure the inlet mainstream velocity, $U_{\infty}$. The standard deviation over the mean $U_{\infty}$ was less than $1 \%$.



(a)

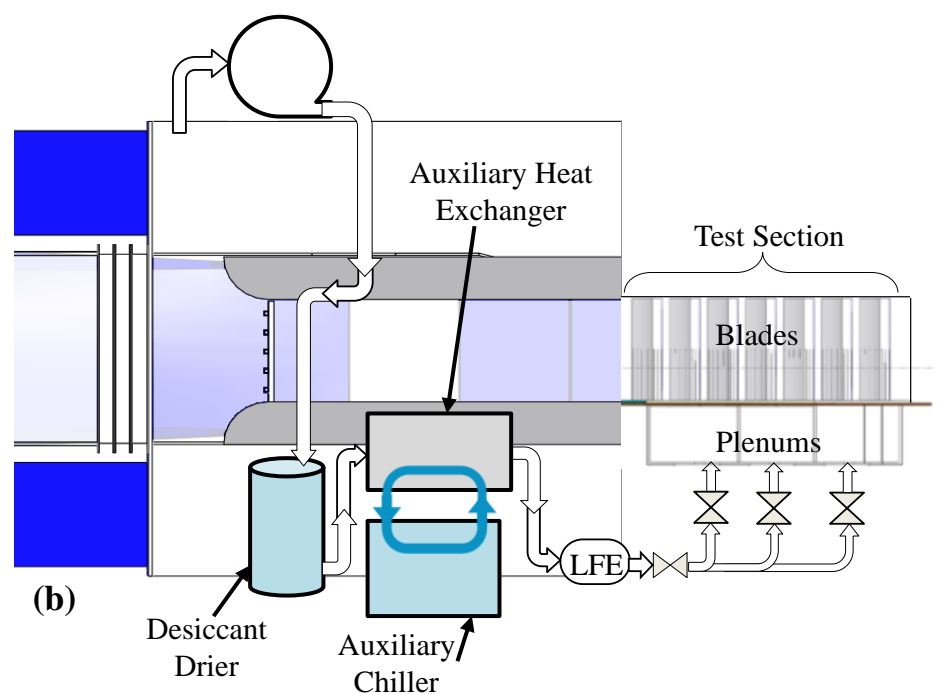

Fig. 2. Depiction of the (a) large-scale low-speed wind tunnel, with a corner test section housing the blade cascade, and (b) the coolant loop with auxiliary cooling capability and the inlet flow development section.

From the top blue channel of the wind tunnel, the coolant was extracted and passed through a drier and a chilled glycol-water heat exchanger as shown in Fig. 2b. A laminar flow element measured the total coolant flowrate, before the flow entered one of three separate plenums below the endwall, which are described in detail later. The configuration shown in Figs. $2 \mathrm{a}$ and $2 \mathrm{~b}$ provided a mainstream to coolant temperature difference of about $40^{\circ} \mathrm{C}$, resulting in a coolant to mainstream density ratio, $D R$, of about 1.15 . The coolant temperature, $T_{c, i n}$, was measured by two thermocouples below the impingement plate whereby the two thermocouples agreed to within $\pm 3^{\circ} \mathrm{C}$ for a typical average $T_{c, i n}=10^{\circ} \mathrm{C}$. When film cooling was included in the endwall, the coolant flowrate was adjusted such that desired film cooling blowing ratio was achieved. Blowing ratios reported in this paper reflected the average blowing ratio over all film cooling holes, $M_{a v g}$. The local blowing ratio for each film cooling hole, $M_{l o c}$, was calculated by scaling the total coolant flowrate by the contribution of each film cooling hole, determined by the local static exit pressure of each hole. For the cases without film cooling, the mass flow rate of coolant was matched to the total mass flow rate corresponding to the $M_{\text {avg }}$ values with film cooling. For a $95 \%$ confidence interval, the uncertainty in coolant flowrate was estimated to be $\pm 3 \%$, using the sequential perturbation method described in Moffat [27].

The top view of the test section is shown in Fig. 3, which shows the seven blade, six passage linear cascade. The blade geometry used was a generic airfoil common in the literature [1,2,22,24,28-36]. The conducting portion of the endwall is shown in green.

Passages 1 and 2 were not used in this study. The center passages, 3 and 4, had film and impingement cooling, so the plenum below these passages contained an impingement plate. Passages 5 and 6 had impingement cooling only, and the coolant was exhausted laterally through a vertical slot below blade 7. The blade geometric parameters are listed in Table 3 along with the inlet mainstream flow conditions. The test section inlet boundary layer parameters were measured at $2.85 \mathrm{C}_{\mathrm{ax}}$ upstream of the center blade by Lynch et al. [24]. To ensure uniformity and periodicity of the cascade, static pressure taps in the blade midspan were used to measure the pressure distribution before all experiments. The measured static pressure around each airfoil agreed well with the inviscid CFD prediction, confirming flow uniformity for all passages [2]. 


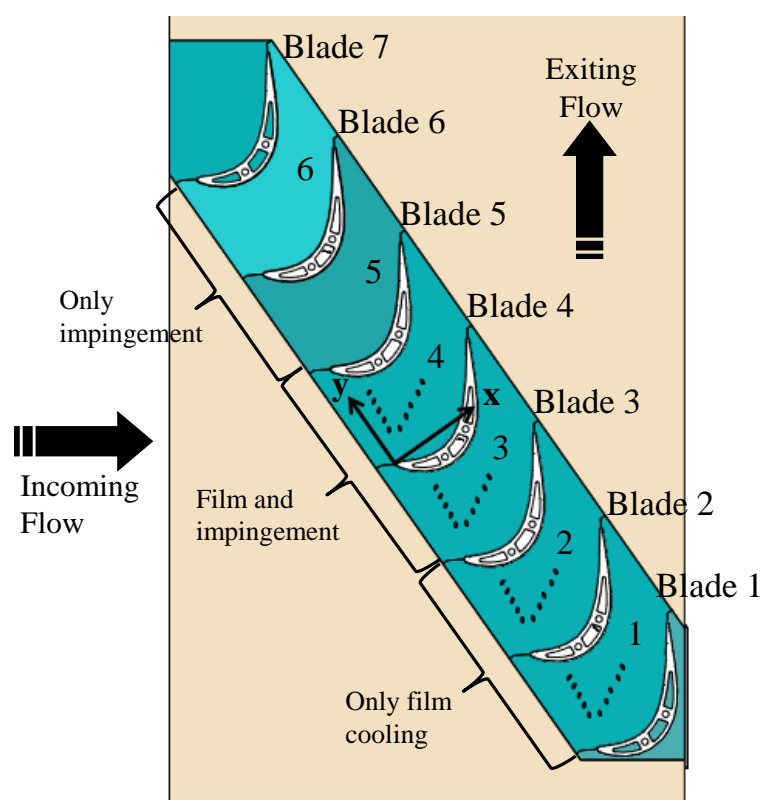

Fig. 3. Schematic of the Pack-B linear blade cascade with blade and passage numbering and top view of the conjugate endwall.

Table 3. Flow Conditions and Blade Geometry

\begin{tabular}{ll|ll}
\hline Scale factor & 8.6 & Inlet, flow angle & $35^{\circ}$ \\
$C_{a x}$ & $0.218 \mathrm{~m}$ & Exit flow angle & $60^{\circ}$ \\
$p / C_{a x}$ & 0.826 & Inlet $M a$ & 0.029 \\
$S / C_{a x}$ & 2.50 & Exit $M a$ & 0.047 \\
Inlet $R e$ & $1.22 \times 10^{5}$ & Inlet $\delta / S$ & 0.061 \\
Exit $R e$ & $1.98 \times 10^{5}$ & Inlet $u^{\prime} / U_{\infty}$ & 0.06 \\
\hline
\end{tabular}

Generic internal and external endwall cooling schemes were used to achieve the matched parameters of $B i$ and $h_{\infty} / h_{i}$ and scaled geometry, shown in Figs. 4a and 4b. Coolant flow is directed into the plenum by means of a splash plate. The coolant flows through an array of 28 holes in the impingement plate. When film cooling is included, the coolant leaves the impingement channel through ten cylindrical film cooling holes angled at $30^{\circ}$ to the endwall surface, corresponding to a hole length-to-diameter ratio, $L / D$, of 5.8 . The diameter, $D$, is the same for the film and impingement holes, $4.4 \mathrm{~mm}$. The cross sectional area of the plenum is over 100 times that of the combined cross sectional area of the impingement holes, and over 300 times that of the combined cross sectional area of the film cooling holes. Figure $4 \mathrm{~b}$ shows the passage location of the impingement jets and film holes. The first row of impingement jets is aligned with the leading edge plane, $\mathrm{x}=0$, and staggered thereafter with a spacing of $4.65 \mathrm{D}$ in both $\mathrm{x}$ - and $\mathrm{y}$-directions. The film cooling hole inlets are located between impingement rows and are separated by the same spacing as the impingement jets. The film cooling holes are oriented in the $x-y$ plane to align with endwall streaklines obtained using oil flow visualization [24]. Figure 4b also identifies the four locations of surface thermocouples on the internal side of the endwall, with red dots. The blue circles show the locations of the $T_{c, \text { inlet }}$ thermocouples, placed in the flow at the entrance to the middle film cooling hole in rows 1 and 2 . Finally, the area outlined in black is used to calculate the area averaged $\phi$ presented in the results. 




Fig. 4. Schematic of internal and external cooling scheme from the side view (a) and the top view (b), also showing area average outline and locations of internal thermocouples.

External surface temperatures on the endwall were measured with steady state infrared (IR) thermography to maximize the spatial measurement resolution and take advantage of the scaled up geometry. The IR camera viewed the endwall from a distance of $56 \mathrm{~cm}$ through removable ports in the ceiling of the test section. At steady-state, five IR images were acquired at each port location. The resolution of each image was 1.3 pixels $/ \mathrm{mm}$ or 5.7 pixels $/ D$. The images were calibrated for emissivity and reflected temperature by minimizing the difference between the image and thermocouples embedded at the endwall outer surface. The emissivity was typically 0.92 because all endwall surfaces were painted with flat black paint. After calibration, the images were assembled into a single endwall temperature map. The uncertainty in $\phi$ was determined to be \pm 0.02 using a confidence interval of $95 \%$ with the partial derivative method [27]. Ribbon-type thermocouples were placed at four locations on the internal endwall surface, to be used in calculating the non-dimensional internal wall temperature, $\phi_{i}$. The internal wall thermocouple locations are presented in Fig. $4 \mathrm{~b}$ with red dots. Using a $95 \%$ confidence interval, the uncertainty in $\phi_{i}$ is estimated to be \pm 0.01 .

\subsection{COMPUTATIONAL METHODS}

Conjugate computational simulations were performed using the commercial computational fluid dynamics (CFD) software FLUENT [37]. The steady-state RANS and energy equations were solved with the segregated pressure-based SIMPLE algorithm and SST k- $\omega$ turbulence model [38] for closure. The SST k- $\omega$ model has shown reasonable agreement with experimental results in turbomachinery applications [12,20,22,39,40]. The computational domain is shown in Fig. 5a. A velocity inlet was applied 3.5 blade axial chords upstream of the blade leading edge. The inlet had a uniform temperature distribution to match the experiments and a mainstream velocity of $10.5 \mathrm{~m} / \mathrm{s}$. The inlet boundary layer profile was generated using the boundary layer code TEXSTAN [41] to match the momentum thickness Reynolds number measured by Lynch et al. [24] 2.85 blade axial chords upstream of the blade leading edge in the inlet flow direction. At the exit of the domain, an outflow boundary condition was applied 1.5 blade axial chords downstream of the blade trailing edge in the x-direction. Symmetry was imposed at the top of the domain, which was located at the midspan of the blade in the experiments. Periodic boundaries were imposed on the sides of the domain, which cut through the middle 
of the passage and internal cooling passages below the endwall. The plenum extended 65D below the impingement plate to reflect the dimensions of the experimental plenum. A mass flow inlet boundary condition was applied at the entrance to the plenum, where the prescribed mass flow rate and temperature matched the experimental conditions for each blowing ratio. The air properties for the flow were determined by incompressible-ideal gas for density and Sutherland's law for viscosity. Polynomial fits were used to incorporate the temperature dependence of the air thermal conductivity and air specific heat. A thermally-coupled wall interface was used at all conjugate solid/fluid boundaries. All other wall surfaces in the domain were modeled as adiabatic.

Separate unstructured grids were generated for the conducting endwall solid and the flow domain. The commercial grid generation software, Pointwise [42], was used for the endwall. The unstructured endwall grid, shown in Fig. 5b, contained 1.5 million cells. The open source grid generation code, Advancing-Front/Local-Reconnection (ALFR3) [43], was used to generate the flow grids. The flow grids were comprised of mainly tetrahedral cells and layers of wall-normal prism cells on key surfaces (the blade, the entire external endwall surface, the internal endwall surface, the film cooling holes, and the impingement holes). To resolve the boundary layer on these surfaces the first grid point was located at a $\mathrm{y}^{+}$less than one. The unstructured flow grid for the case of $H / D=$ 2.9 is depicted in Fig. 5c, which shows a slice in the y-plane through a film cooling hole inlet and an impingement hole, and in Fig. 5d, which shows a slice in the x-plane through the mainstream, film cooling holes, impingement channel, impingement holes, and plenum.
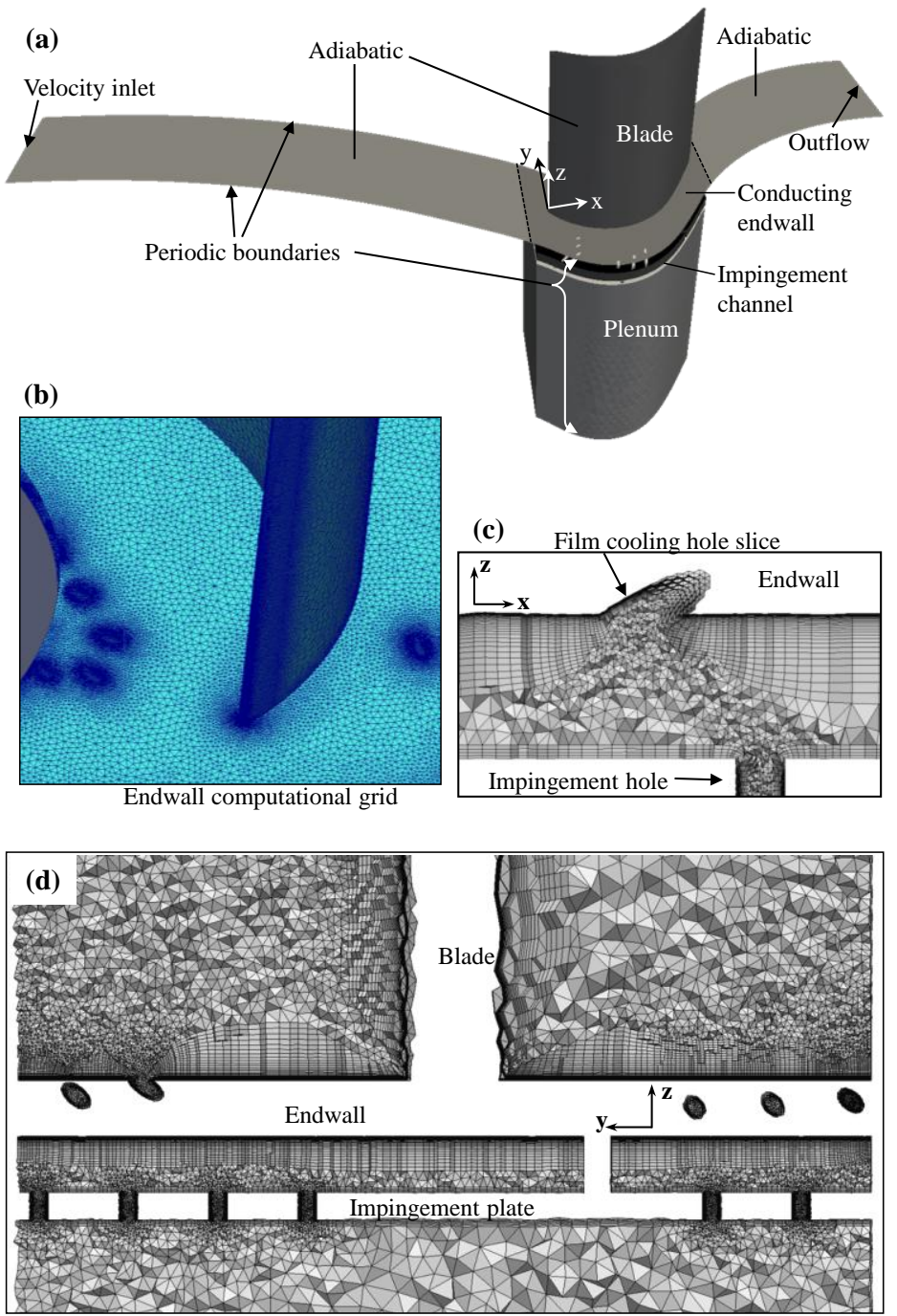

Fig. 5. Depiction for the case of $H / D=2.9$ of (a) the computational domain and boundary conditions, (b) the surface grid for the endwall, (c) the prism layer volume grid in the holes and impingement channel, and (d) the volume grid in the mainstream, channel, and plenum.

The solution was determined to be converged when the normalized residuals reached $1 \times 10^{-4}$ and the area-averaged endwall $\phi$ changed by less than 0.0015 over 500 iterations. A grid independence test was done for the $H / D=2.9$ case. The initial grid of 9.8 million flow cells and 1.5 million endwall cells was uniformly refined to a grid containing a 16.1 million flow cells and 2.5 million endwall cells. For $\mathrm{M}_{\text {avg }}=1$, the area-averaged $\phi$ over the endwall changed by $10^{-4}$ from the initial grid to the refined grid. In addition, 
the total heat flux at the internal endwall surface varied by less than $0.25 \%$ from the initial grid to the refined grid. Therefore, it was concluded that the initial grid of 9.8 million flow cells and 1.5 million endwall cells was of sufficient resolution for the conjugate heat transfer predictions, and the CFD solutions were grid insensitive.

\section{RESULTS AND DISCUSSION}

The effect of varying the height of the impingement channel was investigated for both cases of impingement cooling only and combined impingement and film cooling. Experimental overall effectiveness, $\phi$, results were obtained for $H / D=2.9$ and 0.6 at coolant flowrates corresponding to blowing ratios of $M_{\text {avg }}=1$ and 2. The $R e_{D}$ of the impingement jets were approximately 1000 for $M_{\text {avg }}=1$ and 1900 for $M_{\text {avg }}=2$. Computational $\phi$ predictions were obtained for the combined film and impingement case. Additional impingement channel heights were examined with the computations, including $H / D=5.8$ and 10.2, at blowing ratios of $M_{\text {avg }}=1$ and 2. The trends of $\phi$ and internal Nusselt number, $N u_{D, i}$, with $H / D$ were evaluated, and flow streamlines within the channel were examined to understand the trends.

Measurements of impingement only effectiveness, $\phi_{o}$, are shown along with the impingement hole locations in Fig. 6 for both impingement channel heights and two impingement $R e_{D}$. The flowrates for the cases in Figures $6 \mathrm{a}$ and $6 \mathrm{~b}$ are equivalent to a blowing ratio of 1 when film cooling is included. The flowrates of Figures $6 \mathrm{c}$ and $6 \mathrm{~d}$ correspond to a blowing ratio of 2 . Figures $6 \mathrm{a}$ and $6 \mathrm{c}$ are for $H / D=2.9$ and Figs. $6 \mathrm{~b}$ and $6 \mathrm{~d}$ are for $H / D=0.6$. Figure $6 \mathrm{a}$ specifies direction of coolant exiting the impingement channel under the endwall.

The effectiveness in the center of the impingement cooled area is less for $H / D=0.6$ than for $H / D=2.9$ as shown by the higher $\phi_{o}$ values for Figs. 6a and 6c. This trend with $H / D$ is consistent with the literature for impingement cooling. Heat transfer coefficients slightly increase with $H / D$ up to a peak between 1.5 and $4[3,6]$. With $H / D=0.6$ there is also increased $\phi_{o}$ (cooler wall) on the upstream suction side of the passage compared to $H / D=2.9$. The increase on the upstream suction side is the result of internal cooling by the narrow channel flow that develops as the impingement jets are exhausted in that direction. Along the downstream half of the suction side of the blade, there is elevated effectiveness for all four cases. As the external flow near the endwall goes through the passage, it is swept from toward the suction side due to the large pressure gradient. This external flow develops a thermal boundary layer as it passes over the cooled endwall above the impingement array. The cooler boundary layer fluid provides some cooling downstream of the array, along the downstream half of the suction side of the blade.

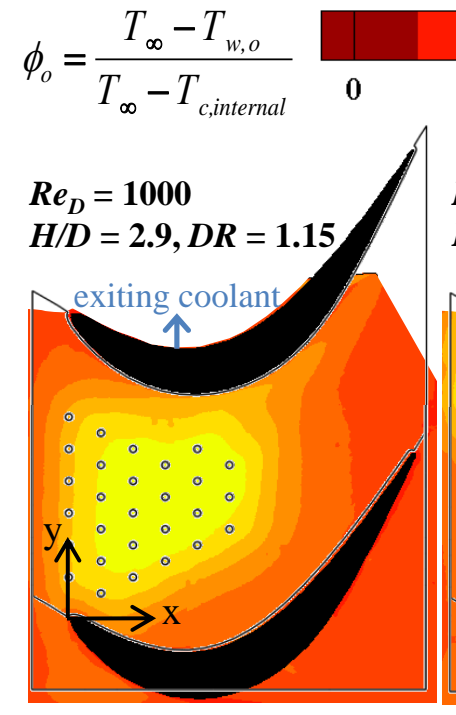

(a)

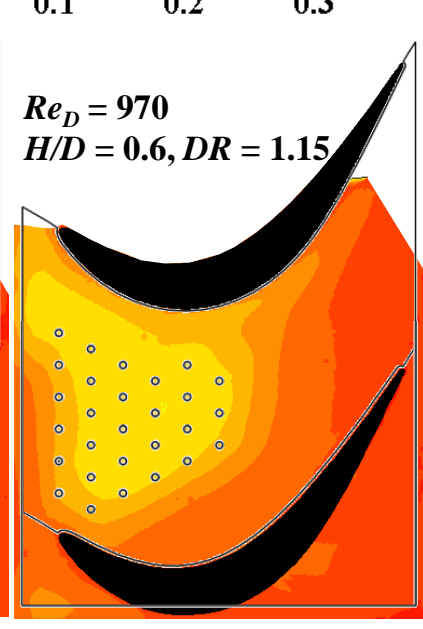

(b)

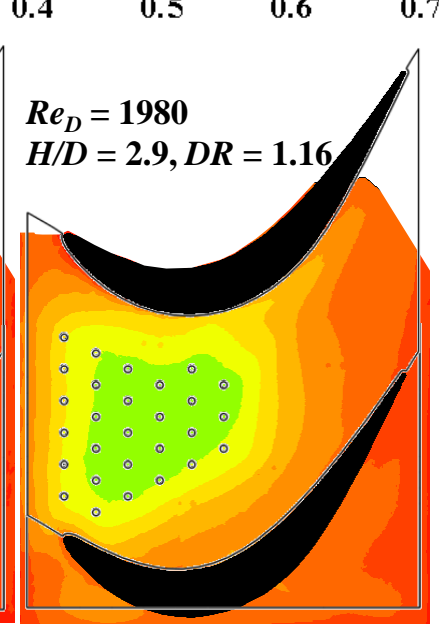

(c)
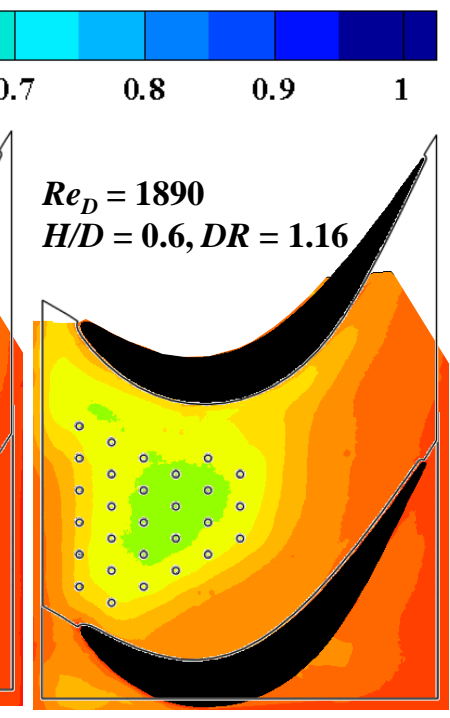

(d)

Fig. 6. Contours of measured $\phi_{o}$ for (a) $M_{\text {avg }}=1.0, H / D=2.9$ (b) $M_{\text {avg }}=1.0, H / D=0.6$ (c) $M_{\text {avg }}=2.0, H / D=2.9$ (d) $M_{\text {avg }}=2.0$, $H / D=0.6$, with $90^{\circ}$ impingement holes and plenum boundaries overlaid.

Measurements of overall effectiveness for combined impingement and film cooling, $\phi$, are also reported for two blowing ratios and two impingement channel heights. Figures $7 \mathrm{a}$ and $7 \mathrm{c}$ show the results for $H / D=2.9$, and Figs. $7 \mathrm{~b}$ and $7 \mathrm{~d}$ show the results for $H / D$ $=0.6$. The contours are presented for two adjacent passages measured in the same experiment. Good agreement between the two passages reinforces confidence in the periodicity of the cascade. The impingement and film cooling hole locations are shown as well as the channel boundaries which prevented coolant from crossing from one passage to another in the channel above the impingement plate. Although there were significant differences in impingement only $\phi_{o}$ for different $H / D, \phi$ is almost indistinguishable between the 
two values of $H / D$ for the combined film cooling and impingement cases. Measurements of the average $N u$ for impingement jets staggered with angled extraction holes are available from Hollworth and Dagan [4] for impingement jet spacing of $5 D$, close to the spacing used in the current study. The $N u$ results for staggered film cooling extraction are unchanged between $H / D=1$ and 2.5 [4], which is consistent with the trends of $\phi$ found in Fig. 7.

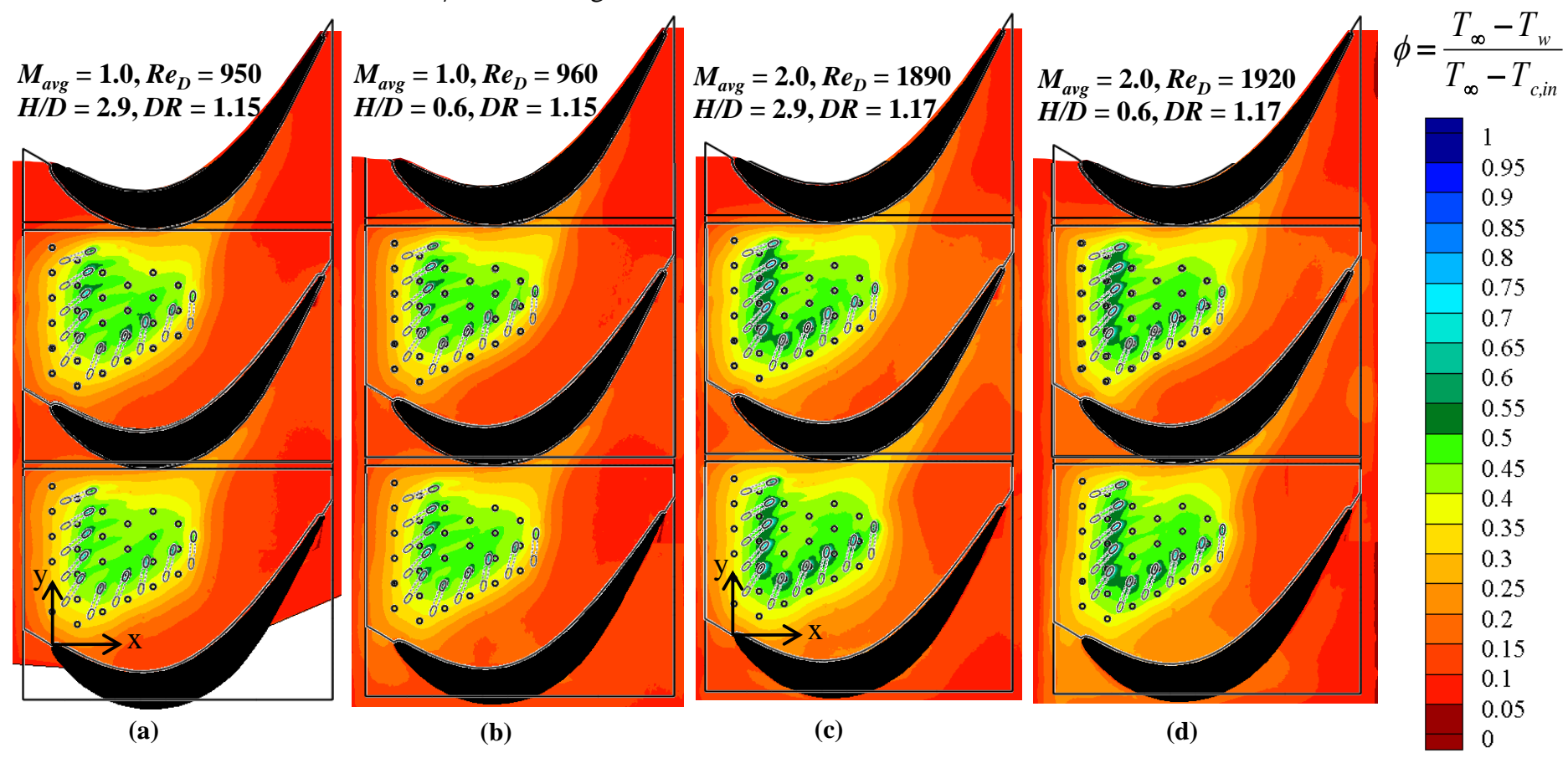

Fig. 7. Contours of measured $\phi$ for (a) $M_{\text {avg }}=1.0, H / D=2.9$ (b) $M_{\text {avg }}=1.0, H / D=0.6$, (c) $M_{\text {avg }}=2.0, H / D=2.9$, (d) $M_{\text {avg }}=2.0$, $H / D=0.6$, with $30^{\circ}$ inclined film holes, $90^{\circ}$ impingement holes, and plenum boundaries overlaid.

The contour data are laterally averaged across the pitch (y) direction and plotted as functions of axial distance in Fig. 8a for impingement only, $\phi_{o}$, and in Fig. $8 \mathrm{~b}$ for combined impingement and film, $\phi$. The plot of impingement only in Fig. 8a shows that the cases with $H / D=0.6$ have higher laterally averaged effectiveness than $H / D=2.9$ upstream of $x / C_{a x}=0.05$. However, for most of the passage $\left(0.1<x / C_{a x}<0.6\right)$, the case with $H / D=0.6$ is less effective. For combined impingement and film cooling in Fig. $8 \mathrm{~b}$, there is no significant change in laterally averaged effectiveness when $H / D$ is varied between 2.9 and 0.6 .



(a)

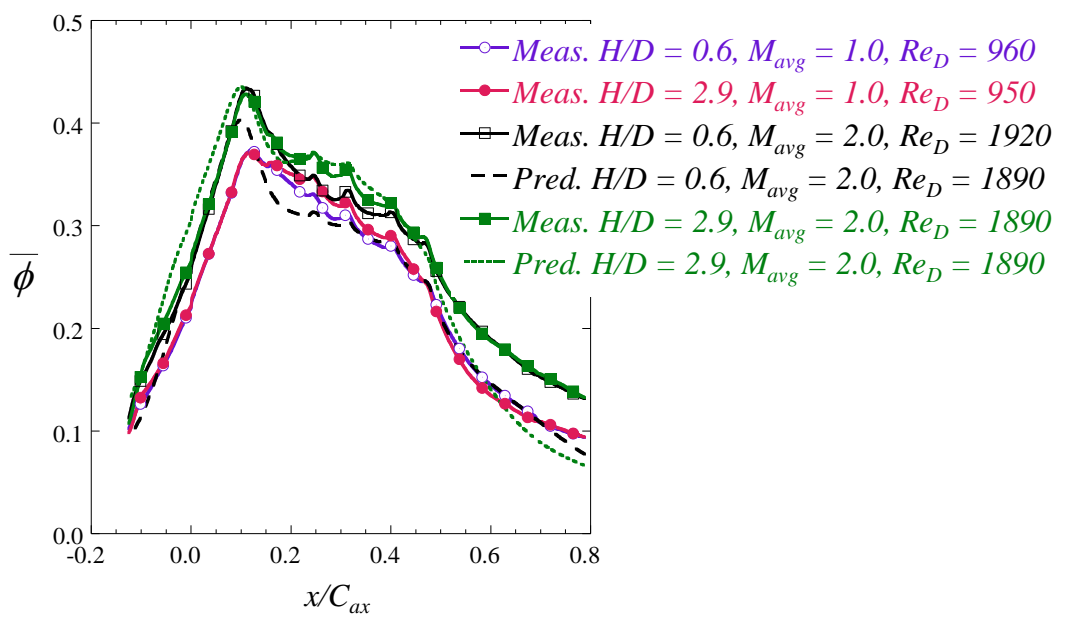

(b)

Fig. 8. Pitchwise laterally averaged effectiveness plotted as a function of axial distance for different values of impingement channel spacing, $H / D$, (a) measured for impingement only, and (b) measured and predicted for film and impingement. 
Computational simulations were completed to investigate the behavior of $\phi$ as $H / D$ was increased beyond 2.9 , to $H / D=5.8$ and 10.2. The $\phi$ contours are shown for all impingement channel heights in Fig. 9, for $M_{\text {avg }}=1$ and 2 . The impingement and film cooling holes and the channel boundaries are overlaid. In comparing the same conditions between Figs. 7 and 9 , the measured $\phi$ and computational predictions were found to match reasonably well, especially for $M_{a v g}=2$, where the computations correctly predict the detachment of the film cooling jets [2]. The agreement for $M_{a v g}=2$ can also be observed in the laterally averaged data in Fig. 8a.

No significant differences exist between $H / D=0.6$ and 2.9 in the predicted contours shown in Figs. 9c, 9d, 9g and 9h, which is a similar trend to the experimental results in Fig. 7. However, for $M_{a v g}=1$ and $H / D=0.6$ in Fig. $9 \mathrm{~d}$, the peak $\phi$ in the center of the impingement area is highest at the smallest $H / D$. As $H / D$ increases, the peak effectiveness decreases, and the area in the center of the impingement array becomes warmer. Although $\phi$ decreases in the center of the impingement area, $\phi$ increases on the pressure side of the passage near the blade with increasing $H / D$. At larger $H / D$, the effect of the impingement cooling spreads to cool a greater portion of the endwall area outside of the impingement array. At the smallest impingement channel height, the impingement cooling produces high effectiveness in the center, but lower effectiveness in the surrounding area. At the largest impingement channel height, the impingement cooling appears to have spread and generate a more uniform effectiveness distribution throughout the impingement and surrounding area. Both the effects of high peak impingement effectiveness with low $H / D$, as well as more uniform effectiveness with high $H / D$ are consequences of the coolant flow behavior between the impingement plate and the bottom of the endwall. These competing effects combine to produce the area averaged trends found in the literature and found in the subsequent discussion of the area averaged overall effectiveness results.

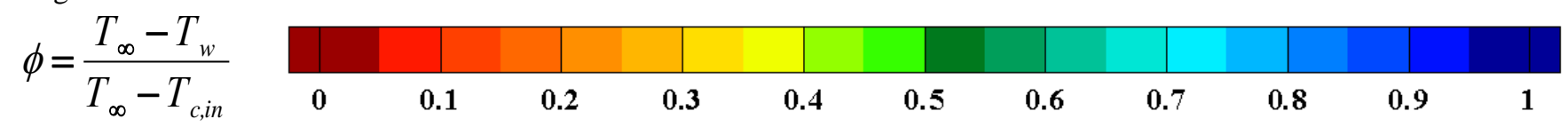

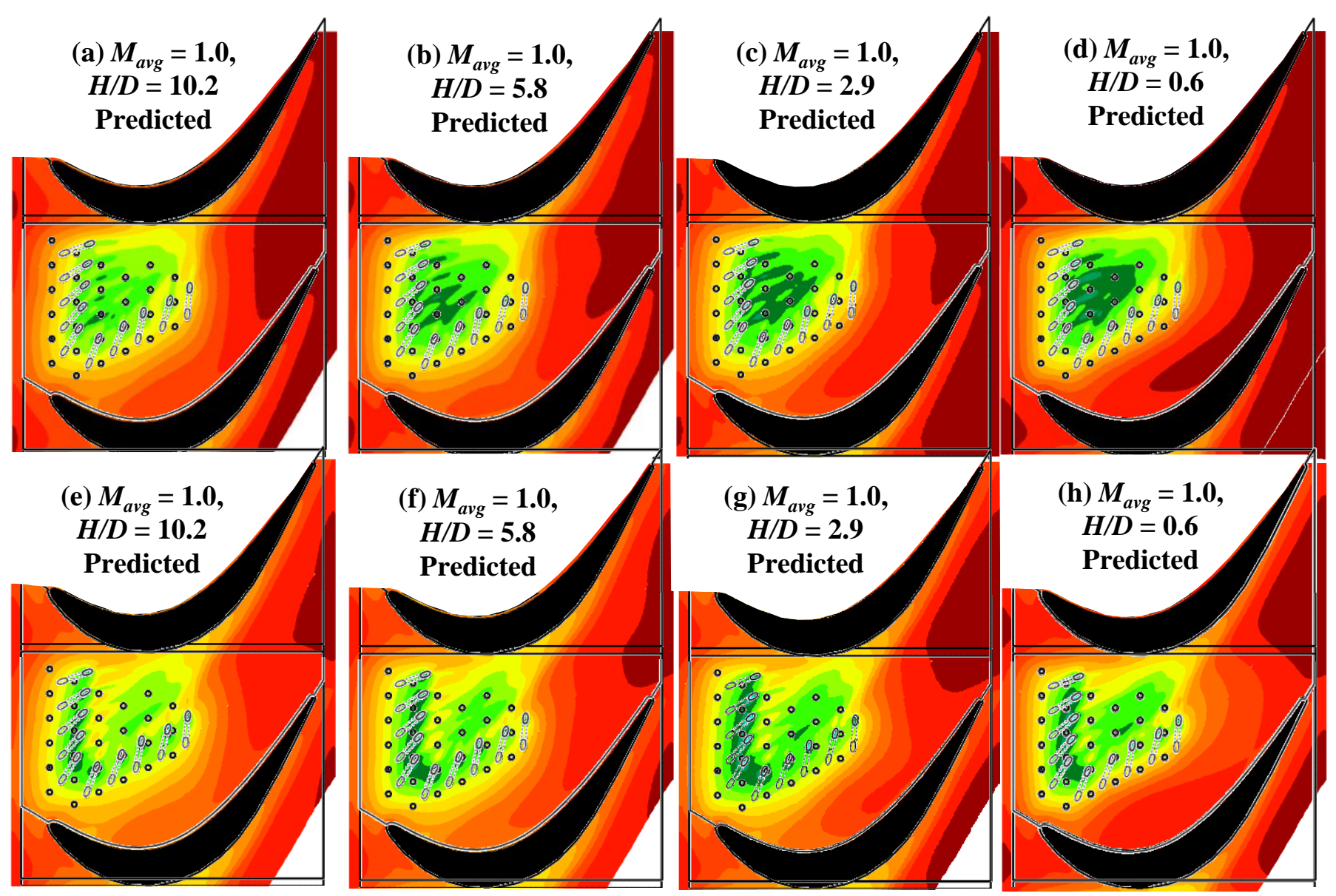

Fig. 9. Contours of predicted $\phi$ for (a) $M_{a v g}=1.0, H / D=2.9,(b) M_{a v g}=1.0, H / D=5.8,(c) M_{a v g}=1.0, H / D=2.9$ (d) $M_{a v g}=1.0$, $H / D=0.6$, (e) $M_{\text {avg }}=2.0, H / D=10.2$, (f) $M_{\text {avg }}=2.0, H / D=5.8(\mathrm{~g}) M_{\text {avg }}=2.0, H / D=2.9,(\mathrm{~h}) M_{\text {avg }}=2.0, H / D=0.6$, with $30^{\circ}$ inclined film holes, $90^{\circ}$ impingement holes, and plenum boundaries overlaid. 
Flow streamlines within the impingement channel are examined to better understand how the $H / D$ affects the impingement cooling. In Fig. 10, the non-dimensional temperatures and in-plane streamlines are given for a slice of the impingement channel at the $x / C_{a x}=0.47$ plane, which passes through the center of the downstream row of impingement holes. The portion of the data shown focuses on the impingement hole in this row closest to the pressure side, as shown in Fig. $10 \mathrm{~d}$. The predictions are provided at $M_{\text {avg }}=$ 2 for $H / D=10.2$ in Fig. 10a, $H / D=2.9$ in Fig. 10 b, and $H / D=0.6$ in Fig. 10c.

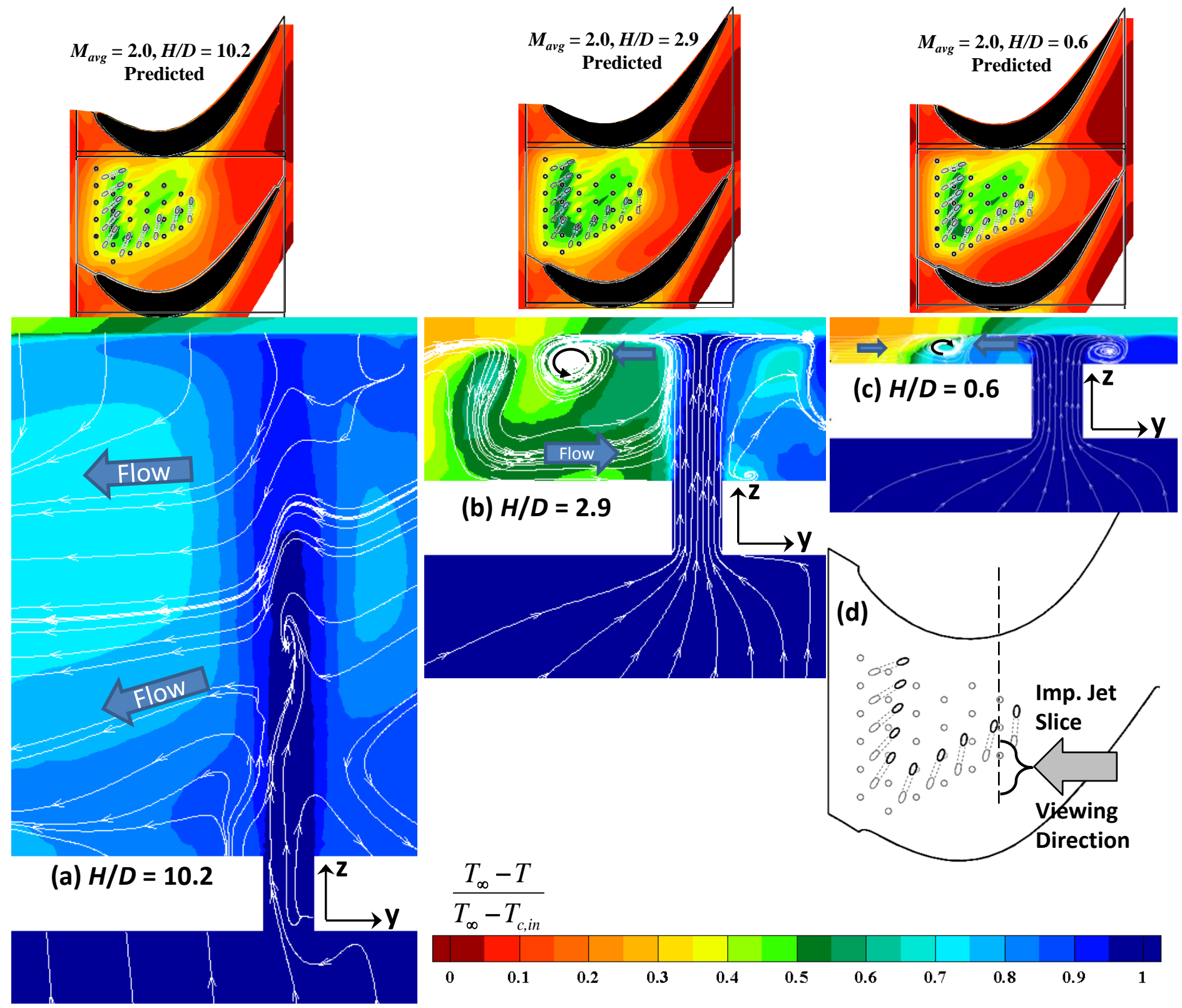

Fig. 10. Predicted in-plane streamlines and contours of non-dimensional temperature in the impingement channel for the first impingement hole in the last row for $M_{a v g}=2.0$ and (a) $H / D=10.2$ (b) $H / D=2.9$, (c) $H / D=0.6$.

The streamlines for the two smaller impingement channel heights, $H / D=0.6$ and 2.9 , exhibit the typical impingement jet behavior. The jet impacts the wall, and then moves away from the center of the jet along the wall, providing effective cooling for the area just above the jet. At the largest channel height, the flow is highly three-dimensional and does not exhibit impingement jet behavior. Also in the case of $H / D=10.2$, the temperature of the flow reaching the endwall is much warmer than the jets in the smaller impingement channels. The warmer temperature and slower velocity of the coolant account for the lower $\phi$ in the area just above the impingement jets as $H / D$ increases. The reason for increased $\phi$ on the pressure side of the passage as $H / D$ increases can also be seen. At the highest channel spacing, Fig. 10a, most of the coolant coming out of the jet flows to left, which is away from the other 
impingement jets and toward the pressure side of the channel. For the smaller $H / D$ in Figs. $10 \mathrm{~b}$ and $10 \mathrm{c}$, there is an inflow of warmer flow from the pressure side which blocks the spreading of the coolant. In the case of $H / D=0.6$, the warmer air from the pressure side circulates counter to the impingement jet flow in a vortex approximately the size of the channel. In the case of $H / D=2.9$, the vortex from the impingement jet flow is about half the height of the channel, so the flow coming from the pressure side can pass under the impingement vortex and mix with the coolant coming from the jet. Figure 10b shows that the temperature of the flow coming from the pressure side of the channel is cooled as it comes toward the jet.

The overall trends with $H / D$ can be assessed by quantifying the area average of the overall effectiveness, which indicates the expected average wall temperature. The area used for the average, outlined in Fig. 4b, surrounds the impingement holes and the portions of the endwall cooled by film cooling. Both the measurements and predictions of $\overline{\bar{\phi}}$ are plotted in Fig. 11 as a function of $H / D$. The measured $\overline{\bar{\phi}}$ is slightly higher for $H / D=2.9$ compared to $H / D=0.6$. The predictions show a larger different in $\overline{\bar{\phi}}$ between the smallest two channel heights than the measurements, but the predicted trend is the same direction as the measurements. As $H / D$ increases beyond 2.9, the predicted $\overline{\bar{\phi}}$ is reduced slightly, but overall there is not a significant change in $\overline{\bar{\phi}}$ for this range of $H / D$.

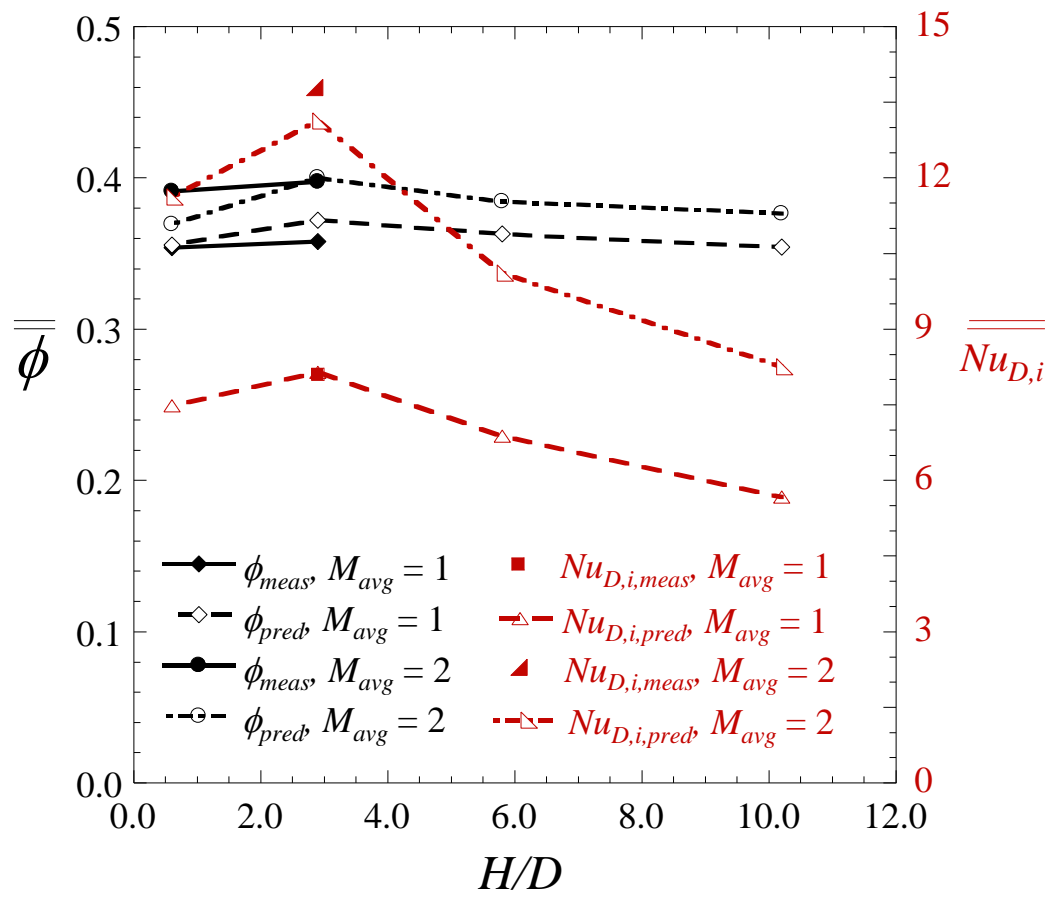

Fig. 11. Measured and predicted area-averaged $\phi$ and $N u_{D, i}$ plotted as a function of impingement channel height for $M_{a v g}=1.0$ and 2.0.

The average internal heat transfer coefficient, $\overline{\overline{h_{i}}}$, was calculated from the measurements of $\phi$ and $\phi_{i}$ at the four locations in Fig. 4 b using Eq. (3) for film and impingement cooling at $H / D=2.9$. The $\overline{\overline{h_{i}}}$ was non-dimensionalized to Nusselt number based on $D$ and the thermal conductivity of the coolant. The coolant thermal conductivity was determined from a polynomial fit of the air conductivity varying with temperature using the measured internal coolant temperature, $T_{c, i n}$. Fig. 11 shows the measured $\overline{\overline{N u_{D, i}}}$ on the right axis at blowing ratios of 1 and 2 for $H / D=2.9$ in solid red symbols. The $N u_{D, i}$ for other impingement channel heights were obtained from the computational predictions using Eq. (4). The predicted $N u_{D, i}$ results are area averaged across the area outlined in Fig. 4 and are given in Fig. 11 in red with open symbols and dotted lines. The measured and predicted $N u_{D, i}$ are in good agreement, especially for $M_{a v g}=1$. Unlike $\bar{\phi}$ there is a clearly defined peak in the area-averaged $N u_{D, i}$ at $H / D=2.9$. The existence of an optimal $H / D$ is consistent with the reported maximum impingement $N u$ in the literature, which occurs between $H / D$ of $1.5-4$ [3,4,6].

\section{CONCLUSIONS}

The current study demonstrated the application of a conjugate methodology to understand the effect of multiple cooling technologies on the overall heat transfer for a gas turbine endwall. This methodology can also be applied to understand other systems that have complex heat transfer interactions. Conjugate experiments and simulations were used to examine the overall cooling effect 
of the impingement channel height-to-diameter ratio in particular. Two channel heights were evaluated in the experiments. For the cases of impingement only, there were local differences in overall effectiveness between the two channel heights, but the overall effectiveness for the cases of film and impingement were indistinguishable. The impingement channel height mattered less to the overall effectiveness of cases with film cooling, compared to the cases with impingement only.

Because the conjugate simulations had good agreement with the measurements for average effectiveness and heat transfer coefficients, the simulations provided predictions of these quantities for a wider range of channel heights. It was found that both the overall effectiveness and the internal heat transfer coefficients peaked at the channel height to diameter ratio of 2.9, similar to previous impingement literature data. The streamlines and temperature contours in the impingement channel showed that the smaller channel heights restrict spreading of the coolant outside of the area above the impingement array. With a larger channel spacing, the impingement flow was more three-dimensional. This type of flow led to reduced effectiveness right above the jet compared to the smaller heights, but increased effectiveness for the surrounding area.

The results from this study confirmed that internal heat transfer coefficients of impingement geometries were sensitive to geometric parameters, such as the impingement channel height. However, the average external surface temperatures of the endwall with combined film and impingement cooling was not particularly sensitive to the impingement channel height. The result of surface temperature insensitivity to impingement channel height provides a useful design consideration for turbine designers because the key metric for evaluating cooling technologies is not the heat transfer coefficient, but the predicted external surface temperature.

\section{ACKNOWLEDGMENTS}

The authors would like to acknowledge support from the U.S. Department of Energy (DOE), National Energy Technology Laboratory (NETL) through the University Turbine Systems Research (UTSR) program. Any opinions, findings, conclusions, or recommendations expressed herein are solely those of the authors and do not necessarily reflect the views of the DOE. The writers would like to thank Mark Zelesky of Pratt \& Whitney, Dr. Brent Craven of Pennsylvania State University, Dr. David Bogard of University of Texas, and Robin Ames of DOE-NETL for their continued communication and support regarding this research.

\section{REFERENCES}

[1] A. Mensch, K.A. Thole, Overall Effectiveness of a Blade Endwall with Jet Impingement and Film Cooling, J. Eng. Gas Turb. Power. 136 (2014) 031901. doi:10.1115/1.4025835.

[2] A. Mensch, K.A. Thole, B.A. Craven, Conjugate Heat Tranfer Measurements and Predictions of a Blade Endwall with a Thermal Barrier Coating, J. Turbomach. 136 (2014) 121003. doi:10.1115/1.4028233.

[3] L.W. Florschuetz, C.R. Truman, D.E. Metzger, Streamwise Flow and Heat Transfer Distributions for Jet Array Impingement with Crossflow, J. Heat Transfer. 103 (1981) 337-342. doi:10.1115/1.3244463.

[4] B.R. Hollworth, L. Dagan, Arrays of Impinging Jets with Spent Fluid Removal through Vent Holes on the Target Surface-Part 1: Average Heat Transfer, J. Eng. Power. 102 (1980) 994-999. doi:10.1115/1.3230372.

[5] B.R. Hollworth, G. Lehmann, J. Rosiczkowski, Arrays of Impinging Jets With Spent Fluid Removal Through Vent Holes on the Target Surface, Part 2: Local Heat Transfer, J. Eng. Power. 105 (1983) 393. doi:10.1115/1.3227428.

[6] R. Viskanta, Heat transfer to impinging isothermal gas and flame jets, Experimental Thermal and Fluid Science. 6 (1993) 111134. doi:10.1016/0894-1777(93)90022-B.

[7] T. Wang, L. Zhao, Discussions of some myths and concerned practices of film cooling research, International Journal of Heat and Mass Transfer. 54 (2011) 2207-2221. doi:10.1016/j.ijheatmasstransfer.2010.11.003.

[8] L.D. Hylton, M.S. Mihelc, E.R. Turner, D.A. Nealy, R.E. York, Analytical and Experimental Evaluation of the Heat Transfer Distribution Over the Surfaces of Turbine Vanes, NASA-CR-168015, 1983.

[9] L.D. Hylton, V. Nirmalan, B.K. Sultanian, R.M. Kauffman, The Effects of Leading Edge and Downstream Film Cooling on Turbine Vane Heat Transfer, NASA-CR-182133, 1988.

[10] E.R. Turner, M.D. Wilson, L.D. Hylton, R.M. Kauffman, Turbine Vane External Heat Transfer. Volume 1: Analytical and Experimental Evaluation of Surface Heat Transfer Distributions with Leading Edge Showerhead Film Cooling, NASA-CR$174827,1985$.

[11] E. Papanicolaou, D. Giebert, R. Koch, A. Schulz, A conservation-based discretization approach for conjugate heat transfer calculations in hot-gas ducting turbomachinery components, International Journal of Heat and Mass Transfer. 44 (2001) 34133429. doi:10.1016/S0017-9310(01)00017-5.

[12] R.K. Panda, B.V.S.S.S. Prasad, Conjugate Heat Transfer From a Flat Plate With Combined Impingement and Film Cooling, in: Proceedings of ASME Turbo Expo, 2012: pp. GT2012-68830.

[13] J.E. Albert, D.G. Bogard, F. Cunha, Adiabatic and Overall Effectiveness for a Film Cooled Blade, in: Proceedings of ASME Turbo Expo, 2004: pp. GT2004-53998.

[14] P.C. Sweeney, J.F. Rhodes, An Infrared Technique for Evaluating Turbine Airfoil Cooling Designs, J. Turbomach. 122 (2000) 170-177. doi:10.1115/1.555438. 
[15] J. Maikell, D. Bogard, J. Piggush, A. Kohli, Experimental Simulation of a Film Cooled Turbine Blade Leading Edge Including Thermal Barrier Coating Effects, J. Turbomach. 133 (2011) 011014. doi:10.1115/1.4000537.

[16] L.D. Dobrowolski, D.G. Bogard, J. Piggush, A. Kohli, Numerical Simulation of a Simulated Film Cooled Turbine Blade Leading Edge Including Conjugate Heat Transfer Effects, in: Proceedings of ASME IMECE, 2009: pp. IMECE2009-11670.

[17] B.D. Mouzon, E.J. Terrell, J.E. Albert, D.G. Bogard, Net Heat Flux Reduction and Overall Effectiveness for a Turbine Blade Leading Edge, in: Proceedings of ASME Turbo Expo, 2005: pp. GT2005-69002.

[18] S. Ravelli, L. Dobrowolski, D.G. Bogard, Evaluating the Effects of Internal Impingement Cooling on a Film Cooled Turbine Blade Leading Edge, in: Proceedings of ASME Turbo Expo, 2010: pp. GT2010-23002.

[19] R.P. Williams, T.E. Dyson, D.G. Bogard, S.D. Bradshaw, Sensitivity of the Overall Effectiveness to Film Cooling and Internal Cooling on a Turbine Vane Suction Side, J. Turbomach. 136 (2014) 031006. doi:10.1115/1.4024681.

[20] T.E. Dyson, D.G. Bogard, S.D. Bradshaw, Evaluation of CFD Simulations of Film Cooling Performance on a Turbine Vane Including Conjugate Heat Transfer Effects, in: Proceedings of ASME Turbo Expo, 2012: pp. GT2012-69107.

[21] M.B. Kang, K.A. Thole, Flowfield Measurements in the Endwall Region of a Stator Vane, J. Turbomach. 122 (2000) 458. doi:10.1115/1.1303703.

[22] S.P. Lynch, K.A. Thole, A. Kohli, C. Lehane, Computational Predictions of Heat Transfer and Film-Cooling for a Turbine Blade With Nonaxisymmetric Endwall Contouring, J. Turbomach. 133 (2011) 041003. doi:10.1115/1.4002951.

[23] R.J. Goldstein, Film Cooling, in: Advances in Heat Transfer, Elsevier, 1971: pp. 321-379.

[24] S.P. Lynch, K.A. Thole, A. Kohli, C. Lehane, Heat Transfer for a Turbine Blade With Nonaxisymmetric Endwall Contouring, J. Turbomach. 133 (2011) 011019. doi:10.1115/1.4000542.

[25] V.L. Eriksen, R.J. Goldstein, Heat Transfer and Film Cooling Following Injection Through Inclined Circular Tubes, J. Heat Transfer. 96 (1974) 239-245.

[26] J.E. Dees, D.G. Bogard, R.S. Bunker, Heat Transfer Augmentation Downstream of Rows of Various Dimple Geometries on the Suction Side of a Gas Turbine Airfoil, J. Turbomach. 132 (2010) 031010. doi:10.1115/1.3149284.

[27] R.J. Moffat, Describing the uncertainties in experimental results, Exp. Therm. Fluid Sci. 1 (1988) 3-17. doi:10.1016/08941777(88)90043-X.

[28] J. Lake, P. King, R. Rivir, Reduction of separation losses on a turbine blade with low Reynolds numbers, in: Proceedings of the AIAA Aerospace Sciences Meeting, 1999: p. AIAA 99-0242. http://dx.doi.org/10.2514/6.1999-242.

[29] C.G. Murawski, K. Vafai, An Experimental Investigation of the Effect of Freestream Turbulence on the Wake of a Separated Low-Pressure Turbine Blade at Low Reynolds Numbers, J. Fluids Eng. 122 (2000) 431-433. doi:10.1115/1.483281.

[30] I. Popovic, J. Zhu, W. Dai, S.A. Sjolander, T. Praisner, E. Grover, Aerodynamics of a Family of Three Highly Loaded LowPressure Turbine Airfoils: Measured Effects of Reynolds Number and Turbulence Intensity in Steady Flow, in: Proceedings of ASME Turbo Expo, 2006: pp. GT2006-91271. doi:10.1115/GT2006-91271.

[31] T.J. Praisner, E. Allen-Bradley, E.A. Grover, D.C. Knezevici, S.A. Sjolander, Application of Non-Axisymmetric Endwall Contouring to Conventional and High-Lift Turbine Airfoils, in: Proceedings of ASME Turbo Expo, 2007: pp. GT2007-27579. doi:10.1115/GT2007-27579.

[32] T. Zoric, I. Popovic, S.A. Sjolander, T. Praisner, E. Grover, Comparative Investigation of Three Highly Loaded LP Turbine Airfoils: Part I - Measured Profile and Secondary Losses at Design Incidence, in: Proceedings of ASME Turbo Expo, 2007: pp. GT2007-27537. doi:10.1115/GT2007-27537.

[33] A. Mahallati, B.R. McAuliffe, S.A. Sjolander, T.J. Praisner, Aerodynamics of a Low-Pressure Turbine Airfoil at Low-Reynolds Numbers: Part 1 - Steady Flow Measurements, in: Proceedings of ASME Turbo Expo, 2007: pp. GT2007-27347. doi:10.1115/GT2007-27347.

[34] T.J. Praisner, E.A. Grover, D.C. Knezevici, I. Popovic, S.A. Sjolander, J.P. Clark, et al., Toward the Expansion of Low-PressureTurbine Airfoil Design Space, in: Proceedings of ASME Turbo Expo, 2008: pp. GT2008-50898. doi:10.1115/GT2008-50898.

[35] D.C. Knezevici, S.A. Sjolander, T.J. Praisner, E. Allen-Bradley, E.A. Grover, Measurements of Secondary Losses in a Turbine Cascade With the Implementation of Nonaxisymmetric Endwall Contouring, J. Turbomach. 132 (2010) 011013. doi:10.1115/1.3072520.

[36] S.A. Lawson, S.P. Lynch, K.A. Thole, Simulations of Multiphase Particle Deposition on a Nonaxisymmetric Contoured Endwall With Film-Cooling, J. Turbomach. 135 (2013) 031032. doi:10.1115/1.4007598.

[37] FLUENT 13.0.0, ANSYS Inc., Cannonsburg, PA, 2010.

[38] F.R. Menter, Two-equation eddy-viscosity turbulence models for engineering applications, AIAA Journal. 32 (1994) $1598-1605$. doi: $10.2514 / 3.12149$.

[39] M. Schwänen, A. Duggleby, Identifying Inefficiencies in Unsteady Pin Fin Heat Transfer, in: Proceedings of ASME Turbo Expo, ASME, 2009: pp. GT2009-60219. doi:10.1115/GT2009-60219.

[40] G. Snedden, D. Dunn, G. Ingram, D. Gregory-Smith, The Application of Non-Axisymmetric Endwall Contouring in a Single Stage, Rotating Turbine, in: Proceedings of ASME Turbo Expo, ASME, 2009: pp. GT2009-59169. doi:10.1115/GT2009-59169.

[41] M.E. Crawford, TEXSTAN (academic version), University of Texas, Austin, TX, 2009. 
[42] Pointwise 17.1r3, Pointwise, Inc., Fort Worth, TX, 2013.

[43] D. Marcum, J. Gaither, Mixed Element Type Unstructured Grid Generation for Viscous Flow Applications, in: AIAA Computational Fluid Dynamic Conference, Norfolk, VA, 1999: p. AIAA 1999-3252. 